\title{
Detection and identification of enteroviruses circulating in children with acute gastroenteritis in Pará State, Northern Brazil (2010-2011)
}

\author{
Raiana Scerni Machado 1,2, Ivanildo Pedro de Sousa Jr. ${ }^{2}$, Jacqueline Cortinhas Monteiro 1,3, James Lima Ferreira', \\ Jainara Cristina dos Santos Alves ${ }^{1}$ and Fernando Neto Tavares ${ }^{1 *}$
}

\begin{abstract}
Although acute gastroenteritis (AGE) has been reported as a common infectious disease in children, there is scarce information about enterovirus (EV) circulating associated with AGE cases in Brazil. The purpose of the present study was to identify and characterize the enteroviruses associated with AGE in children in Belém, Brazil. A total of 175 stool samples were obtained from children hospitalized revealing the presence of EV in 26.3\% (46/175) of infections. EV type was identified in 78.3\% (36/46) and EV-B species (61.1\%; 22/36) was the most prevalent EV-detected followed by EV-C (25\%; 9/36) and EV-A (13.9\%; 5/36). This study has provided important information about the enterovirus circulation in Pará state, Northern Brazil.
\end{abstract}

Keywords: Enterovirus, Acute gastroenteritis, Brazil

Acute gastroenteritis (AGE) is one of the most common diseases in humans, mainly in children and remains as important cause of morbidity and mortality among infants around the world [1]. Children under 5 years old are the most affected with highest incidence and leading cause of million deaths annually worldwide, occurring mainly in low as well as in middle-income countries [2]. In Brazil, AGE also presents higher morbidity rates representing a significant cause of death in the first year of life [3-5]. AGE can be caused by a variety of infectious agents (viral, bacterial, protozoan) as well as non-infectious agents [4]. Among the viral agent, rotavirus, calicivirus, norovirus, adenovirus and astrovirus have been demonstrated as the most frequent causes of AGE in children [6, 7]. Recently, different members of the Picornaviridae family, such as Parechovirus, Cosavirus, Salivirus and Aichivirus have been identified as agents associated

\footnotetext{
*Correspondence: fernandotavares@iec.gov.br

${ }^{1}$ Laboratório de Referência Regional em Enteroviroses, Seção de Virologia, Instituto Evandro Chagas, Ananindeua, Pará, Brasil

Full list of author information is available at the end of the article
}

with diarrhea in humans $[8,9]$. The Picornaviridae family also has the Enterovirus genus, whose association with AGE has been recognized and reported in many studies $[1,7,10]$. Although enteroviruses (EV) infections are mostly asymptomatic, these viral agents can cause severe infection, such as syndromes of the central nervous system, myocarditis and neonatal sepsis [10].

In Brazil, a limited number of studies on EV that are associated with AGE have been reported [11, 12]. These works were based on description only one specific type, hence, the epidemiological analysis of EV infection in AGE patients is restricted. Thus, the purpose of this study was to identify the circulating genotypes of EV isolated from children with AGE symptoms in Belém (Pará state), Northern region from Brazil providing valuable information about EV circulation.

From May 2010 through April 2011, 175 stool specimens were collected from children $(<5$ years) who had been suffering from AGE and attended to the Pediatric Clinic of Pará. Viral RNA was extracted (Viral Nucleic Acid Extraction Kit-QIAmp-Qiagen) directly from the clinical specimens and initially subjected to a original author(s) and the source, provide a link to the Creative Commons licence, and indicate if changes were made. The images or other third party material in this article are included in the article's Creative Commons licence, unless indicated otherwise in a credit line to the material. If material is not included in the article's Creative Commons licence and your intended use is not permitted by statutory regulation or exceeds the permitted use, you will need to obtain permission directly from the copyright holder. To view a copy of this licence, visit http://creativecommons.org/licenses/by/4.0/. The Creative Commons Public Domain Dedication waiver (http://creativeco mmons.org/publicdomain/zero/1.0/) applies to the data made available in this article, unless otherwise stated in a credit line to the data. 
broad-reactive real time RT-PCR (rRT-PCR) for human enteroviruses as previously described [13, 14]. EV-positive samples $(46 / 175 ; 26.3 \%)$ in the rRT-PCR were submitted to viral isolation in RD and HEp2-C cell lines and incubated at $37^{\circ} \mathrm{C}$ and examined daily for cytopathic effect (CPE) with total destruction of the cell monolayer, which is a characteristics of enterovirus infection. Conventional PCR was performed using a pair of primers (222 and 292) that amplifies a fragment of approximately 350 bp within the VP1 gene, as described [14, 15].

After inoculation, the specimens that did not have effect in the production of CPE $(30 / 46 ; 65.2 \%)$ were submitted to a semi-nested PCR (RT-snPCR) amplification of partial VP1 gene according to previously described $[14,16]$. EV-positive amplicons from RT-sn PCR (22/30; 73.3\%) and conventional PCR/cell culture (16/46; 34.8\%) (Table 1) were cycle-sequenced by the Sanger method using a BigDye Terminator v3.1 Cycle Sequencing Kit (Applied Biosystems), and the nucleotide sequences obtained were compared with those available in the GenBank database to determine the viral types. In general, we were able to identify EV type in $78.3 \%(36 / 46)$ of the samples, which revealed a detection pattern EV-B (61.1\%; 22/36) > EV-C (25\%; 9/36) > EV-A (13.9\%; 5/36) (Table 2). These findings were similar to previous reports that showed EV-B species more frequently detected than EV-C and EV-A species in children with AGE [18-20]. Some EV positive samples in rRT-PCR could not be typed $(8 / 46 ; 17.4 \%)$ due to failure to produce amplicons. Additionally, two other specimens showed a problem in genotyping. Sequences of the primers used in this study for EV detection are shown in Table 3. Noteworthy that the specimens were tested for other viral agents, such as rotavirus, parechovirus and aichivirus and the coinfection EV and non-enterovirus was observed with aichivirus.

CVB3, E7 and E9 were the most frequently detected type from the EV-positive specimens (Table 2).

Table 1 Specimens used in this study obtained from patients with AGE symptoms, and laboratory results

\begin{tabular}{|c|c|c|c|c|}
\hline $\begin{array}{l}\text { Type } \\
\text { of specimens }\end{array}$ & $\begin{array}{l}\text { N. } \\
\text { specimens }\end{array}$ & $\begin{array}{l}\text { Results } \\
\text { by: rRT- } \\
\text { PCR;cell } \\
\text { culture; } \\
\text { RTsn-PCR } \\
\text { (positive/ } \\
\text { specimens) }\end{array}$ & EV positive & $\begin{array}{l}\text { EV positive } \\
\text { rates }(\%)\end{array}$ \\
\hline Stool & 175 & $\begin{array}{c}46 / 175 \\
16 / 46 \\
22 / 30\end{array}$ & 46 & $26.3(46 / 175)$ \\
\hline
\end{tabular}

Table 2 Enterovirus types associated with AGE in children hospitalized in Pará State, Brazil

\begin{tabular}{lll}
\hline Species & Type & N. total (\% of total) \\
\hline A & CVA5 & $2(5.5)$ \\
& CVA6 & $2(5.5)$ \\
CVA10 & $1(2.7)$ \\
B & & $5(13.9)$ \\
& CVA9 & $1(2.7)$ \\
& CVB3 & $4(11.1)$ \\
& CVB4 & $2(5.5)$ \\
& E3 & $1(2.7)$ \\
& E6 & $1(2.7)$ \\
& E7 & $4(11.1)$ \\
E9 & $4(11.1)$ \\
Total & E14 & $1(2.7)$ \\
Subtotal & E15 & $2(5.5)$ \\
C & E18 & $1(2.7)$ \\
& E25 & $1(2.7)$ \\
& & $22(61.1)$ \\
& CVA13 & $2(5.5)$ \\
& EV-C96 & $1(2.7)$ \\
& EV-C99 & $3(8.3)$ \\
& PV1 & $1(2.7)$ \\
& PV3 & $2(5.5)$ \\
& $9(25)$ \\
& & $36(100)$ \\
& &
\end{tabular}

Furthermore, it is worth mentioning the high detection rate of EV-C species and the identification of uncommon types, such as EV-C99 and EV-C96, mainly identified in Hep2C cell line. These results suggest the importance of the Hep2C cell culture in the NPEVs surveillance as previously reported, which can favor an increased number of EV-C isolates [21].

In this study, $26.3 \%(46 / 175)$ of specimens analyzed were EV-positive. Similar results were obtained from studies performed in India, which reported an EV detection rate of 33-40\% [22]. Surprisingly, although it has been shown that enteroviruses can be associated with AGE cases in children, the high detection rate as observed in this study is not common. This difference can be due to viral detection methods and seasonal factors. This result suggests that the circulating of these viruses may not be well known in children in Belém.

To further analyze EV types identified in AGE patients, we carried out a phylogenetic analysis based on partial VP1 sequences (Fig. 1). CVA5, CVA6 and CVA10 strains circulating in Belém were closely related to viruses detected in Japan, China and The Netherlands (Fig. 1a). 
Table 3 Sequences of the Primers used in Real-Time PCR, CDNA synthesis, PCR amplification and sequencing for EV detection

\begin{tabular}{|c|c|c|c|}
\hline Primer/ Probe & Sequence $^{a}$ & Gene & Location $^{\mathbf{b}}$ \\
\hline EVReal $T(A)^{c}$ & GCGATTGTCACCATWAGCAGYCA & $5^{\prime}-$ UTR & $599-577$ \\
\hline EVRealT(S) ${ }^{\mathbf{c}}$ & GGCCCCTGAATGCGGCTAATCC & $5^{\prime}$-UTR & $449-470$ \\
\hline PanEVProbe $(S)^{c}$ & FAM-CCGACTACTTTGGGWGTCCGTGT-MGBNFQ & $5^{\prime}$-UTR & $537-559$ \\
\hline AN32 ${ }^{d}$ & GTYTGCCA & VP1 & $3009-3002$ \\
\hline AN33 ${ }^{d}$ & GAYTGCCA & VP1 & $3009-3002$ \\
\hline AN34 ${ }^{d}$ & CCRTCRTA & VP1 & $3111-3104$ \\
\hline AN35 ${ }^{d}$ & RCTYTGCCA & VP1 & $3009-3002$ \\
\hline $222^{d}$ & CICCIGGIGGIAYRWACAT & VP1 & 1977-1996 \\
\hline $224^{d}$ & GCIATGYTIGGIACICAYRT & VP3 & 2969-2951 \\
\hline $292^{d}$ & MIGCIGYIGARACNGG & VP1 & $2612-2627$ \\
\hline AN88 ${ }^{d}$ & TACTGGACCACCTGGNGGNAYRWACAT & VP1 & $2977-2951$ \\
\hline AN89 d & CCAGCACTGACAGCAGYNGARAYNGG & VP1 & $2602-2627$ \\
\hline
\end{tabular}

a Degenerate primers: $\mathrm{Y}=\mathrm{C}$ or $\mathrm{T} ; \mathrm{R}=\mathrm{A}$ or $\mathrm{G} ; \mathrm{W}=\mathrm{A}$ or $\mathrm{T} ; \mathrm{M}=\mathrm{A}$ or $\mathrm{C} ; \mathrm{N}=\mathrm{A}, \mathrm{C}, \mathrm{G}$ or $\mathrm{T} ; \mathrm{I}=$ Inosine;

b The locations of all primers are relative to the genome of poliovirus type 1, Mahoney strain;

c [17];

d $[14,16]$

Regarding EV-B species, the strains evaluated in this study were classified as shown in Fig. 1b. The Brazilian sequences were grouped into different clusters according to type and had a relative close relationship with previously strains circulating mainly in Europe and Asian (Fig. 1b). The phylogenetic analysis of the EV-C species isolates of this study revealed that the Brazilian strains were related to viruses previously circulating in China, Finland and Uruguay (Fig. 1c). The polioviruses found in this work (PV1 and PV3) were analyzed to a nucleotide divergence and revealed a high homology to Sabin-like viruses (Fig. 1c).

\section{Conclusion}

Overall, this work provides valuable information about the circulation and the genetic diversity of EV associated with AGE cases, reinforcing the need of tailoring current surveillance strategies to timely monitor emergence/ re-emergence of non-polio enteroviruses. Furthermore, the data obtained from monitoring of diarrhea cases can reveal important information on the PV circulation (Sabin, VDPV or wild type) in areas of low vaccine coverage and deficient acute flaccid paralysis surveillance. Additionally, in the context of global eradication of polioviruses, information on non-polio enteroviruses circulation is key to understand their role in AGE context and other enteroviruses infections-associated. The difficult in the access the patient records and to survey other causative agents involved in AGE represented a study limitation. 

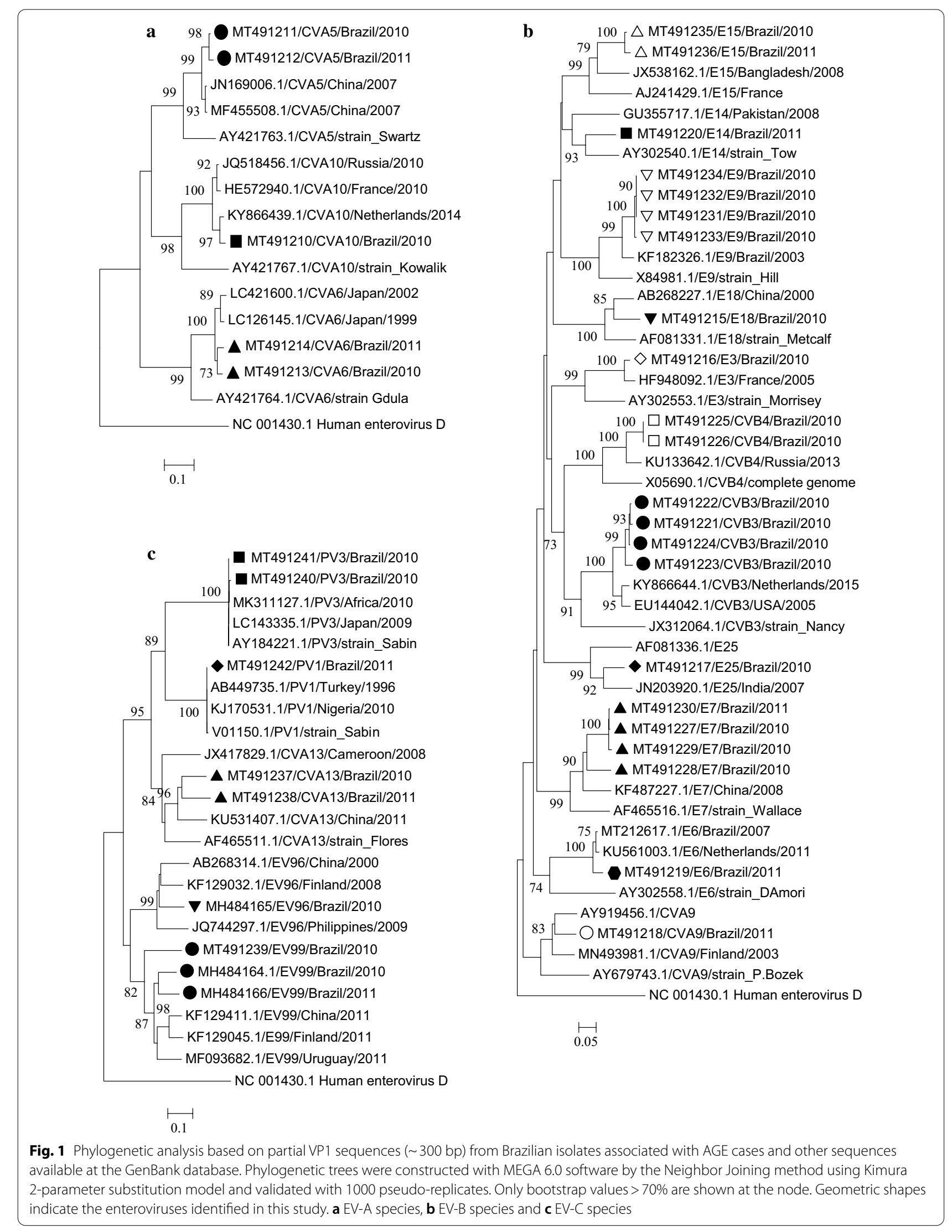


\section{Abbreviations}

AGE: Acute gastroenteritis; EV: Enterovirus; CV: Coxsackievirus; E: Echovirus; PV: Poliovirus; VDPV: Vaccine-derived poliovirus.

\section{Acknowledgements}

The authors would like to thank all the laboratory technicians who somehow participated in this study, especially Antônia Alves, Edna da Silveira and Euda Galiza.

\section{Authors' contributions}

RSM and FNT conceived and designed the experiments and participated in the sequence alignment. IPS, RSM and FNT prepared the original draft. JCM, $J L F, J C S A$ and RSM conducted the experiments. All authors read and approved the final manuscript.

\section{Funding}

This work was funded by the National Council for Scientific and Technological Development (CNPq) and by the Evandro Chagas Institute, Ministry of Health, Ananindeua, Pará, Brazil.

\section{Availability of data and materials}

The data analyzed during the current study are available from the corresponding author on reasonable request.

\section{Ethics approval and consent to participate}

This work was submitted to and approved by the IEC/SVS/MS Human Research and Ethics Committee under number 87223 in compliance with resolution 466/12

\section{Consent for publication}

Not applicable.

\section{Competing interests}

The authors declare that there are no conflicts of interest.

\section{Author details}

${ }^{1}$ Laboratório de Referência Regional em Enteroviroses, Seção de Virologia, Instituto Evandro Chagas, Ananindeua, Pará, Brasil. ${ }^{2}$ Laboratório de Enterovírus, Instituto Oswaldo Cruz, Fundação Oswaldo Cruz, Rio de Janeiro, Brasil. ${ }^{3}$ Laboratório de Virologia, Instituto de Ciência Biológicas, Universidade Federal do Pará, Belém, Pará, Brasil.

Received: 30 June 2020 Accepted: 7 October 2020

Published online: 16 October 2020

\section{References}

1. Das JK, Salam RA, Bhutta ZA. Global burden of childhood diarrhea and interventions. Curr Opin Infect Dis. 2014;27(5):451-8.

2. Qazi S, Aboubaker S, MacLean R, et al. Ending preventable child deaths from pneumonia and diarrhoea by 2025. Development of the integrated Global Action Plan for the Prevention and Control of Pneumonia and Diarrhoea. Arch Dis Child. 2015;100(Suppl. 1):S23-8.

3. Filho EP, da Costa Faria NR, Fialho AM, et al. Adenoviruses associated with acute gastroenteritis in hospitalized and community children up to 5 years old in Rio de Janeiro and Salvador, Brazil. J Med Microbiol. 2017:56:313-9.

4. Cantelli CP, da Silva MFM, Fumian TM, et al. High genetic diversity of noroviruses in children from a community-based study in Rio de Janeiro, Brazil, 2014-2018. Arch Virol. 2019;164(5):1427-514.

5. Pratte-Santos R, Miagostovich MP, Fumian TM, et al. High prevalence of enteric viruses associated with acute gastroenteritis in pediatric patients in a low-income area in Vitória, Southeastern Brazil. J Med Virol. 2019;91(5):744-50.

6. Dennehy PH. Acute diarrheal disease in children: epidemiology, prevention, and treatment. Infect Dis Cli North Am. 2005;19(3):585-602.

7. Goodgame RW. Viral causes of diarrhea. Gastroenterol Clin N Am. 2001;30:779-95.
8. Nielsen AC, Gyhrs ML, Nielsen LP, et al. Gastroenteritis and the novel picornaviruses aichi virus, cosavirus, saffoldvirus, and salivirus in young children. J Clin Virol. 2013:57(3):239-42.

9. Yip CC, Lo KL, Que TL, et al. Epidemiology of human parechovirus, Aichivirus and salivirus in fecal samples from hospitalized children with gastroenteritis in Hong Kong. Virol J. 2014;11:182.

10. Tapparel C, Siegrist F, Petty TJ, et al. Picornavirus and enterovirus diversity with associated human diseases. Infect Genet Evol. 2013;14:282-93.

11. Ribeiro GO, Luchs A, Milagres FAP, et al. Detection and Characterization of Enterovirus B73 from a Child in Brazil. Viruses. 2019;11:16.

12. Luchs A, Leal E, Tardy K, et al. The rare enterovirus C99 and echovirus 29 strains in Brazil: potential risks associated to silent circulation. Mem Inst Oswaldo Cruz. 2019;114:e190160.

13. Sousa IP Jr, Burlandy FM, Ferreira JL, et al. Re-emergence of a coxsackievirus $\mathrm{A} 24$ variant causing acute hemorrhagic conjunctivitis in Brazil from 2017 to 2018. Arch Virol. 2019;164(4):1181-5.

14. WHO. Enterovirus Surveillance Guidelines - guidelines for enterovirus surveillance in support of the polio eradication. Regional Office for Europe: World Health Organization; 2015. p. 2015.

15. Oberste MS, NixWA, Maher K, et al. Improved molecular identification of enteroviruses by RT-PCR and amplicon sequencing. J Clin Virol. 2003;26:375-7

16. Nix WA, Oberste MS, Pallansch MA. Sensitive, seminested PCR amplification of VP1 sequences for direct identification of all enterovirus serotypes from original clinical specimens. J Clin Microbiol. 2006;44:2698-704.

17. Kilpatrick DR, Yang CF, Ching K, et al. Rapid group-, serotype-, and vaccine strain-specific identification of poliovirus isolates by real-time reverse transcription-PCR using degenerate primers and probes containing deoxyinosine residues. J Clin Microbiol. 2009;47(6):1939-41.

18. Chansaenroj J, Tuanthap S, ThanusuwannasakT, et al. Human enteroviruses associated with and without diarrhea in Thailand between 2010 and 2016. PLoS ONE. 2017;12(7):e0182078.

19. Pham NTK, Thongprachum A, Trinh QD, et al. Detection and genetic characterization of enterovirus strains circulating among children with acute gastroenteritis in Japan during 2014-2016. Infect Genet Evol. 2018:61:16-9.

20. Coutinho CRM, Siqueira JAM, Machado RS, et al. Enterovirus detection and serotyping of fecal material collected from three children living on the outskirts of Belém city, Amazon region, Brazil, during the first 3 years of life (1983-1986). J Med Virol. 2019. https://doi.org/10.1002/jmv.25656.

21. Bessaud M, Pillet S, Ibrahim W, et al. Molecular characterization of human enteroviruses in the Central African Republic: uncovering wide diversity and identification of a new human enterovirus A71 genogroup. J Clin Microbiol. 2012;50(5):1650-8.

22. Chitambar S, Gopalkrishna V, Chhabra P, et al. Diversity in the enteric viruses detected in outbreaks of gastroenteritis from Mumbai, Western India. Int J Environ Res Public Health. 2012:9(3):895-915.

\section{Publisher's Note}

Springer Nature remains neutral with regard to jurisdictional claims in published maps and institutional affiliations.

Ready to submit your research? Choose BMC and benefit from:

- fast, convenient online submission

- thorough peer review by experienced researchers in your field

- rapid publication on acceptance

- support for research data, including large and complex data types

- gold Open Access which fosters wider collaboration and increased citations

- maximum visibility for your research: over 100M website views per year

At BMC, research is always in progress.

Learn more biomedcentral.com/submissions 